\title{
MENGHITUNG KEUNTUNGAN MAKSIMAL DARI PENJUALAN ROTI ABON GULUNG DENGAN MENGGUNAKAN METODE SIMPLEKS DAN SOFTWARE POM-QM
}

\author{
Matheus Supriyanto Rumetna ${ }^{1}$, Tirsa Ninia Lina ${ }^{1}$, \\ Satrya Dwi Cahya ${ }^{2}$, Billy Mikael Liwe², Miftakul Kosriyah ${ }^{2}$ \\ ${ }^{1}$ Dosen Fakultas Ilmu Komputer, Universitas Victory Sorong \\ ${ }^{2}$ Mahasiswa Fakultas Ilmu Komputer, Universitas Victory Sorong \\ Email: ${ }^{1}$ matheus.rumetna@gmail.com
}

\begin{abstract}
Abstrak
Roti abon gulung merupakan contoh dari beberapa produk kuliner asli asal Timur Indonesia khususnya di wilayah Papua Barat. Produk ini juga dapat di jadikan buah tangan para wisatawan yang berkunjung di Papua Barat dan tidak menutup kemungkinan bisa di beli untuk di konsumsi sehari-hari entah itu sarapan, makan siang, makan malam, ataupun di jadikan snack. Tujuan mendirikan usaha tersebut agar menjaga nilai-nilai budaya di wilayah tersebut dan meningkatkan perekonomian daerah, oleh sebab itu di perlukan teknik atau metode dalam menentukan kenuntungan maksimal. Metode simpleks merupakan metode yang digunakan dalam penelitian ini serta memanfaatkan teknologi informasi yaitu penggunaan tools POM-QM untuk menghitung perkiraan keuntungan biaya penjualan serta pengiriman produk tersebut.
\end{abstract}

Kata kunci: Maksimalisasi, Keuntungan, Metode Simpleks, POM-QM

\begin{abstract}
Abstrak
Abstract Shredded bread rolls are examples of some original culinary products from Eastern Indonesia, especially in the region of West Papua. This product can also be made by tourists visiting West Papua and it is possible to buy it for daily consumption whether it's breakfast, lunch, dinner, or snack. The purpose of establishing the business is to preserve the cultural values in the region and improve the regional economy, so that it is therefore necessary to have a technique or method in determining the maximum profit. The simplex method is the method used in this study and utilizes information technologyuse of POM-QM tools to calculate the estimated cost of selling and shipping the product.
\end{abstract}

Keywords: Maximization, Profit, Simplex Method, POM-QM

\section{PENDAHULUAN}

Usaha penjualan roti abon gulung Hawai Bakery merupakan salah satu cara untuk meningkatkan kesejahteraan hidup masyarakat dan mengenalkan contoh dari beberapa produk kuliner khas Timur Indonesia khususnya di wilayah Papua Barat, Indonesia. Abon merupakan pengolahan makanan yang bahan utamanya seperti daging atau ikan dicincang dan dikeringkan dengan menambahkan bumbu-bumbu tertentu. Inovasi dari produk abon seperti roti abon gulung dapat menjadi suatu usaha yang menjanjikan (Ismail and Putra, 2017).

Abon merupakan salah satu produk olahan yang sudah dikenal banyak orang. Menurut SNI 013707-1995, abon adalah suatu jenis makanan kering berbentuk khas yang dibuat dari daging ikan yang direbus dan disayatsayat, diberi bumbu, digoreng, kemudian dipres. Pada prinsipnya, abon merupakan suatu produk pengawetan, yaitu kombinasi antara perebusan dan penggorengan dengan menambahkan bumbu-bumbu. Produk yang dihasilkan mempunyai tekstur, aroma, dan rasa yang khas. Selain itu, proses pembuatan abon merupakan proses pengurangan kadar air dalam bahan pangan yang bertujuan untuk memperpanjang proses penyimpanan (Jusniati, Patang and Kadirman, 2017).

Tujuan penelitian ini adalah untuk menghitung keuntungan maksimal dari penjualan roti abon gulung Hawai Bakery. Serta untuk mengetahui penggunaan metode simpleks pada kendala yang dialami usaha penjualan roti abon gulung Hawai Bakery.

Dalam penelitian ini menggunakan salah satu metode dalam Pemrograman Linier yaitu metode 
simpleks. Metode simpleks dikembangkan oleh George Dantzing pada tahun 1947. (Budiyanto, Mujiharjo and Umroh, 2017). Metode simpleks adalah penyelesaian masalah pemrograman linier dengan jalan mencari penyelesaian yang layak, dan menggunakan prosedur iteratif, mengembangkan pemecahan hingga dihasilkan penyelesaian yang optimal (Nasution et al., 2016). Pemrograman linier (PL) adalah suatu bentuk model matematika yang menggunakan Teknik bahasa pemrograman untuk menyusun dan menyelesaikan permasalahan optimasi dengan fungsi objektif dan kendala yang bersifat linier (Chandra, 2015) (Firmansyah et al., 2018).

Model Pemrograman linear terdiri dari komponen dan karakteristik tertentu. Komponen model termasuk variable keputusan, fungsi tujuan dan batasan model. Variabel keputusan adalah simbol matematika yang menggambarkan tingkatan aktifitas perusahaan, misalnya perusahaan roti ingin memproduksi roti keju (X1) dan roti coklat (X2), di mana X1 dan X2 adalah lambang yang menunjukkan jumlah variabel setiap item yang tidak diketahui (Budiasih, 2018).

Selain menggunakan PL, penelitian ini juga menggunakan software POM-QM for windows untuk mempermudah menentukan dan menghitung keuntungan maksimum yang diperoleh dari setiap penjualan yang dilakukan oleh Toko Abon Gulung Hawai dalam jangka waktu satu hari dengan tepat, sehingga memiliki perhitungan yang akurat dan diharapkan dapat mempermudah dan mempercepat proses perhitungan (Rumetna et al., 2019).

\section{METODE PENELITIAN}

Adapun langkah-langkah dalam proses penelitian, yaitu (Rico Ong et al., 2019) (Rumetna et al., 2018)

1) Identifikasi Masalah.

Masalah yang dihadapi oleh penjualan produk roti abon gulung adalah memaksimalkan keuntungan dengan keterbatasan biaya pengiriman serta harga penjualan yang mesti di sesuaikan.

2) Pemilihan Model Pemecahan Masalah Model yang digunakan dalam pemecahan masalah yang telah teridentifikasi adalah model Program Linear (PL) permasalahan maksimasi dengan metode simpleks secara manual dan menggunakan tools analisis POM-QM for Windows.

3) Pengumpulan Data

Pengumpulan data dilakukan melalui studi lapangan seperti observasi, interview, dan dokumentasi dengan karyawan toko penjualan produk tersebut agar mendapatkan data yang akan di proses.

Data yang dibutuhkan dalam penelitian ini berupa harga tiket pengiriman, harga pabrik per tiap produk, biaya gaji karyawan, produksi yang dihasilkan, serta jumlah produksi keuntungan produk per satuan produksi.
4) Pengolahan Data dan Analisis

Pengolahan data dan analisis mengunakan metode simpleks pada PL dengan tools analisis POM-QM for Windows.

5) Implementasi Model

Tahap implementasi model adalah mempersiapkan model matematik untuk permasalahan maksimasi keuntungan.

Pemodelan dilakukan dengan mengidentifikasi variabel keputusan, fungsi tujuan dan fungsifungsi kendala (constraint)

6) Evaluasi Hasil

Evaluasi hasil dilakukan dengan menganalisis hasil analisis PL yang dihasilkan oleh tools POMQM pada penjualan roti abon gulung berdasarkan data yang terkumpul.

\section{7) Melaksanakan Solusi Terpilih}

Tahap pelaksanaan solusi terpilih bukan bagian dari penelitian, maka langkah pengambilan keputusan hanya sampai pada tahap evaluasi hasil. Tahap melaksanakan solusi merupakan wewenang dari pihak penjual Roti Abon Hawai Bakery.

Hasil dari pemodelan dapat digunakan sebagai pertimbangan pengambilan keputusan terkait permasalahan produksi yang dialami pengusaha penjualan roti abon gulung, bukan sebagai keputusan yang bersifat mutlak harus direalisasikan.

langkah-langkah di atas dapat dilihat dengan jelas pada Gambar 1.

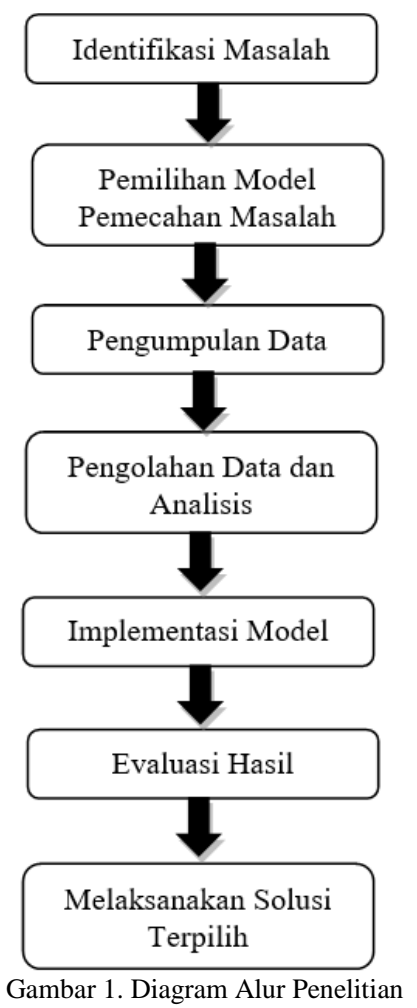




\section{ANALISA DAN HASIL}

Berdasarkan data dari penjualan Roti Abon Gulung Hawai, dapat dilakukan pengelompokan atau identifikasi terhadap variabel keputusan yaitu:

1. Roti Abon Gulung Sapi, memerlukan:

1) Banyak Barang 40 box

2) Berat Box $48 \mathrm{~kg}$

2. Roti Abon Gulung Sapi, memerlukan:

1) Banyak Barang 20 box

2) Berat Box $24 \mathrm{~kg}$

Banyak barang diasumsikan bahwa permintaan konsumen sesuai dengan jumlah penjualan. Sementara keuntungan per produk yang diperoleh adalah:

1. Roti Abon Gulung Sapi Rp.180,000,-

2. Roti Abon Gulung Ayam Rp.170,000,-

Sedangkan persediaan bahan baku adalah:

3. Banyak Barang 100 box

4. Berat Box $120 \mathrm{~kg} \mathrm{~kg}$

Untuk menentukan formulasi di atas, digunakan simbol X1, X2, dan Z dimana :

$\mathrm{X} 1$ = Roti Abon Gulng Sapi

$\mathrm{X} 2$ = Roti Abon glung Ayam

Zmax = jumlah keuntungan roti abon gulung sapi dan roti abon gulung ayam

Tujuan penjualan roti abon gulung adalah untuk memperoleh keuntungan sebesar-besarnya dari kendala keterbatasan yang dimiliki. Maka formulasi model matematisnya adalah:

Memaksimumkan $\quad Z=180.000 X 1+$ $170.000 \times 2$

Keterbatasan dibuat formulasi batasan-batasan sebagai berikut (dapat juga dilihat pada Tabel 1):

Tabel 1

Bahan Baku, Jenis Produk Dan Laba

\begin{tabular}{cccc}
\hline \multirow{2}{*}{ Kendala } & \multicolumn{2}{c}{ JenisProduk } & \\
\cline { 2 - 3 } & $\begin{array}{c}\text { Abon } \\
\text { sapi }\end{array}$ & $\begin{array}{c}\text { Abon } \\
\text { ayam }\end{array}$ & Kapasitas \\
\hline Banyak Box & 40 & 20 & 100 \\
Berat Box & 48 & 24 & 120 \\
\hline $\begin{array}{c}\text { Keuntungan } \\
(\mathrm{Rp})\end{array}$ & 180.000 & 170.000 & \\
\hline
\end{tabular}

Data Tabel 1 dapat dibuat penyelesaian PL persoalan maksimum, langkah-langkah penyelesaiannya adalah sebagai berikut:

1. $40 X 1+20 X 2 \leq 100$

$40 X 1+20 X 2=100$

2. $48 X 1+24 X 1 \leq 120$

$48 X 1+24 X 1=120$

Fungsi tujuan diubah menjadi:

$$
Z-180.000 X 1-170.000 X 2=0
$$

Fungsi batasan diubah dengan memberikan variable slack menjadi:

$$
\begin{gathered}
\text { 1. } 40 X 1+20 X 2 \leq 100 \quad \text { diubah menjadi } \\
40 X 1+20 X 2+S 1=100 \\
\text { 2. } 48 X 1+24 X 1 \leq 120 \quad \text { diubah menjadi } \\
48 X 1+24 X 1+S 2=120
\end{gathered}
$$

Persamaan-persamaan di atas disusun ke dalam table simpleks untuk mengetahui formulasi dari permasalahan (lihat Tabel 2):

Tabel 2

Formulasi

\begin{tabular}{ccccccc}
\hline Var & $\mathrm{Z}$ & $\mathrm{X} 1$ & $\mathrm{X} 2$ & $\mathrm{~S} 1$ & $\mathrm{~S} 2$ & $\mathrm{NK}$ \\
\hline $\mathrm{Z}$ & 1 & -180000 & -170000 & 0 & 0 & 0 \\
$\mathrm{~S} 1$ & 0 & 40 & 20 & 1 & 0 & 100 \\
$\mathrm{~S} 2$ & 0 & 48 & 24 & 0 & 1 & 120 \\
\hline
\end{tabular}

3. Memilih kolom kunci, yaitu: yang mempunyai nilai-nilai pada garis fungsi tujuan yang bernilai negatif dengan angka terbesar (lihat Tabel 3):

Tabel 3

Kolom Kunci

\begin{tabular}{ccccccc}
\hline Var & $\mathrm{Z}$ & $\mathrm{X} 1$ & $\mathrm{X} 2$ & $\mathrm{~S} 1$ & $\mathrm{~S} 2$ & $\mathrm{NK}$ \\
\hline $\mathrm{Z}$ & 1 & -180000 & - & 0 & 0 & 0 \\
S1 & 0 & 40 & 20 & 1 & 0 & 100 \\
S2 & 0 & 48 & 24 & 0 & 1 & 120 \\
\hline \multicolumn{7}{c}{$\hookrightarrow$ Kolom Kunci }
\end{tabular}

Karena nilai X1 merupakan angka negatif paling tinggi yaitu -180000 maka kolom X1 merupakan kolom pivot dan X1 merupakan variabel masuk.

4. Memilih baris kunci, yaitu: nilai yang mempunyai limit rasio dengan angka terkecil (lihat Tabel 4).

\begin{tabular}{|c|c|c|c|c|c|c|c|}
\hline Var & Z & $\mathrm{X} 1$ & $\mathrm{X} 2$ & $\mathrm{~S} 1$ & S2 & NK & $\begin{array}{l}\text { Limit } \\
\text { Rasio }\end{array}$ \\
\hline $\mathrm{Z}$ & 1 & $\begin{array}{c}- \\
180000\end{array}$ & $\begin{array}{c}- \\
170000\end{array}$ & 0 & 0 & 0 & \\
\hline $\mathrm{S} 1$ & 0 & 40 & 20 & 1 & 0 & 100 & $5 / 2$ \\
\hline $\mathrm{S} 2$ & 0 & 48 & 24 & 0 & 1 & 120 & $5 / 2$ \\
\hline
\end{tabular}

Limit Rasio = nilai kanan/nilai kolom kunci $\mathrm{NK}=$ nilai kanan

Tabel 4

Baris Kunci

$\mathrm{X} 1=$ Kolom Kunci

$\mathrm{S} 1=$ Baris Kunci

Limit rasio merupakan hasil dari pembagian antara nilai kanan dengan nilai kolom kunci.

Rasio pembagian nilai kanan paling kecil adalah 1,2

5. Mengubah nilai pada baris kunci Nilai pertama adalah nilai baris pivot baru yaitu X1, semua nilai pada baris S1 dibagi dengan 40 (elemen pivot).

Keterangan:

1) Nilai baris kunci / angka kunci 
2) Nilai kunci yaitu: nilai pada baris $\mathrm{S} 1$

Kolom baris kunci. Angka kunci, yaitu: variabel keluar/elemen pivot (40).

Nilai baris kunci diubah dengan cara dibagi dengan angka kunci, yaitu:
1) $\frac{0}{40}=0$
2) $\frac{40}{40}=1$
3) $\frac{20}{40}=1 / 2$
4) $\frac{1}{40}=1 / 40$
5) $\frac{0}{40}=0$
6) $\frac{100}{40}=5 / 2$

Iterasi 1, hasil pembagian dimasukkan pada baris baru yaitu X1 dimana baris S1 diubah menjadi baris X1 (lihat Tabel 5).

Tabel 5

Perubahan Baris Kunci

\begin{tabular}{ccccccc}
\hline Var & $\mathrm{Z}$ & $\mathrm{X} 1$ & $\mathrm{X} 2$ & $\mathrm{~S} 1$ & $\mathrm{~S} 2$ & $\mathrm{NK}$ \\
\hline $\mathrm{Z}$ & & & & & & \\
$\mathrm{X} 1$ & 0 & 1 & $1 / 2$ & $1 / 40$ & 0 & $5 / 2$ \\
$\mathrm{~S} 2$ & & & & & & \\
\hline
\end{tabular}

6. Mengubah nilai-nilai selain pada baris kunci.

Baris baru $=$ baris lama - (koefisien per kolom kunci $*$ nilai baris kunci).

Keterangan:

a. Baris lama $=$ baris Z, dan baris S2

b. Koefisien per kolom kunci yaitu: -180.000 dan 48

c. Nilai baris kunci= nilai pada baris kunci baru (X1)

Perhitungan nilai baris:

Baris Z

\begin{tabular}{llllll}
\hline $\mathrm{Z}$ & -180000 & -170000 & 0 & 0 & 0 \\
\hline $\mathrm{X} 1$ & 1 & $1 / 2$ & $1 / 40$ & 0 & $5 / 2$ \\
\hline
\end{tabular}

Hasil baris baru adalah:
a. $-180.000-(-180.000 * 1)=0$
b. $-170.000-(-180.000 * 1 / 2)=$ $-80000$
c. $\quad 0-(-180.000 * 1 / 40)=4500$
d. $\quad 0-(-180.000 * 0)=0$
e. $0-(-180.000 * 5 / 2)=450000$

Hasil perhitungan nilai baris baru $(\mathrm{Z})$

\begin{tabular}{llllll}
\hline $\mathrm{Z}$ & 0 & -80000 & 4500 & 0 & 450000 \\
\hline
\end{tabular}

Baris S2

\begin{tabular}{llllll}
\hline $\mathrm{S} 2$ & 48 & 24 & 0 & 1 & 120 \\
\hline $\mathrm{X} 1$ & 1 & $1 / 2$ & $1 / 40$ & 0 & $5 / 2$
\end{tabular}

Hasil baris baru adalah:
a. $48-(48 * 1)=0$
b. $24-(48 * 1 / 2)=0$
c. $\quad 0-\left(48 * \frac{1}{40}\right)=-6 / 5$
d. $\quad 1-(48 * 0)=1$
e. $120-(48 * 5 / 2)=0$

Hasil perhitungan nilai baris baru (S2)

\begin{tabular}{llllll}
\hline S2 & 0 & 0 & $-6 / 5$ & 1 & 0 \\
\hline
\end{tabular}

Masukkan nila- nilai baris baru ke dalam tabel ( lihat Tabel 6).

Tabel 6

Perubahan Nilai-Nilai Baris Baru

\begin{tabular}{cccccccc}
\hline Var & $\mathrm{Z}$ & $\mathrm{X} 1$ & $\mathrm{X} 2$ & $\mathrm{~S} 1$ & $\mathrm{~S} 2$ & $\mathrm{NK}$ & $\begin{array}{l}\text { Limit } \\
\text { Rasio }\end{array}$ \\
\hline $\mathrm{Z}$ & 1 & 0 & -80000 & 4500 & 0 & 450000 & \\
$\mathrm{X} 1$ & 0 & 1 & $1 / 2$ & $1 / 40$ & 0 & $5 / 2$ & \\
$\mathrm{~S} 2$ & 0 & 0 & 0 & $-6 / 5$ & 1 & 0 & \\
\hline
\end{tabular}

Kemudian melakukan perbaikan- perbaikan langkah (3-6) sehingga baris pada kolom Z tidak ada yang bernilai negatif.

7. Memilih kolom kunci Dapat dilihat (pada Tabel 7).

Tabel 7

Kolom Kunci

\begin{tabular}{ccccccc}
\hline Var & $\mathrm{Z}$ & $\mathrm{X} 1$ & $\mathrm{X} 2$ & $\mathrm{~S} 1$ & $\mathrm{~S} 2$ & $\mathrm{NK}$ \\
\hline $\mathrm{Z}$ & 1 & 0 & - & 4500 & 0 & 450000 \\
$\mathrm{X} 1$ & 0 & 1 & $1 / 2$ & $1 / 40$ & 0 & $5 / 2$ \\
$\mathrm{~S} 2$ & 0 & 0 & 0 & $-6 / 5$ & 1 & 0 \\
\hline
\end{tabular}

8. Memilih baris kunci Dapat dilihat (pada Tabel 8).

Tabel 8

Baris Kunci

\begin{tabular}{|c|c|c|c|c|c|c|c|}
\hline Var & $\mathrm{Z}$ & $\mathrm{X} 1$ & $\mathrm{X} 2$ & $\mathrm{~S} 1$ & S2 & NK & $\begin{array}{l}\text { Limit } \\
\text { Rasio }\end{array}$ \\
\hline $\mathrm{Z}$ & 1 & 0 & $\begin{array}{c}- \\
80000\end{array}$ & 4500 & 0 & 450000 & \\
\hline $\mathrm{X} 2$ & 0 & 1 & $1 / 2$ & $1 / 40$ & 0 & $5 / 2$ & 5 \\
\hline $\mathrm{S} 2$ & 0 & 0 & 0 & $-6 / 5$ & 1 & 0 & $\infty$ \\
\hline
\end{tabular}

9. Mengubah nilai pada baris kunci
1) $\frac{0}{1 / 2}=0$
2) $\frac{1}{1 / 2}=2$
3) $\frac{1 / 2}{1 / 2}=1$ 
10 Jurnal Jendela Ilmu, Vol. 1, No. 1, Juni 2020, hlm. 6-12
4) $\frac{1 / 40}{1 / 2}=1 / 20$
5) $\frac{0}{1 / 2}=0$
6) $\frac{5 / 2}{1 / 2}=5$

Iterasi 2, hasil pembagian dimasukkan pada baris baru yaitu X2 dimana baris X1 diubah menjadi baris X2 (lihat Tabel 9).

Tabel 9

Perubahan Baris Kunci

\begin{tabular}{ccccccc}
\hline Var & $\mathrm{Z}$ & $\mathrm{X} 1$ & $\mathrm{X} 2$ & $\mathrm{~S} 1$ & $\mathrm{~S} 2$ & $\mathrm{NK}$ \\
\hline $\mathrm{Z}$ & & & & & & \\
$\mathrm{X} 2$ & 0 & 2 & 1 & $1 / 20$ & 0 & 5 \\
$\mathrm{~S} 2$ & & & & & & \\
\hline
\end{tabular}

10. Mengubah nilai-nilai selain pada baris kunci.

\section{Baris Z}

\begin{tabular}{llllll}
\hline $\mathrm{Z}$ & 0 & -80000 & 4500 & 0 & 450000 \\
\hline $\mathrm{X} 2$ & 2 & 1 & $1 / 20$ & 0 & 5
\end{tabular}

Hasil baris baru adalah:

a. $0-(-180000 * 2)=160000$

b. $-180000-(-180000 * 1)=0$

c. $4500-(-180000 * 1 / 20)=8500$

d. $\quad 0-(-180000 * 0)=0$

e. $450000-(-180000 * 5)=850000$

Hasil perhitungan nilai baris baru $(\mathrm{Z})$

\begin{tabular}{cccccc}
\hline $\mathrm{Z}$ & 160000 & 0 & 8500 & 0 & 850000 \\
\hline
\end{tabular}

\section{Baris S2}

\begin{tabular}{cccccc}
\hline $\mathrm{S} 2$ & 0 & 0 & $-6 / 5$ & 1 & 0 \\
\hline $\mathrm{X} 2$ & 2 & 1 & $1 / 20$ & 0 & 5 \\
\hline
\end{tabular}

Hasil baris baru adalah:
a. $\quad 0-(0 * 2)=0$
b. $\quad 0-(0 * 1)=0$
c. $-\frac{6}{5}-\left(0 * \frac{1}{20}\right)=-6 / 5$
d. $1-(0 * 0)=1$
e. $0-(0 * 5)=0$

Hasil perhitungan nilai baris baru (S2)

\begin{tabular}{llllll}
\hline S2 & 0 & 0 & $-6 / 5$ & 1 & 0
\end{tabular}

Maka tabel iterasi ditunjukkan pada tabel dibawah. Perhitungan tabel iterasi ke 2 sudah optimal maka perhitungan dihentikan setelah nilai pada fungsi tujuan $(Z)$ semua bernilai positif (dapat dilihat pada Tabel 10).
Tabel 10

Hasil Optimisasi

\begin{tabular}{cccccccc}
\hline Var & $\mathrm{Z}$ & $\mathrm{X} 1$ & $\mathrm{X} 2$ & $\mathrm{~S} 1$ & $\mathrm{~S} 2$ & $\mathrm{NK}$ & $\begin{array}{l}\text { Limit } \\
\text { Rasio }\end{array}$ \\
\hline $\mathrm{Z}$ & 1 & 160000 & 0 & 8500 & 0 & 850000 & \\
$\mathrm{X} 2$ & 0 & 2 & 1 & $1 / 20$ & -0 & 5 & \\
$\mathrm{~S} 2$ & 0 & 0 & 0 & $-6 / 5$ & 1 & 0 & \\
\hline
\end{tabular}

Berdasarkan tabel diatas, baris $\mathrm{Z}$ tidak ada lagi yang bernilai negatif sehingga solusi yang diperoleh optimal, maka keuntungan maksimum yang diperoleh penjualan roti abon gulung dari perhitungan dengan menggunakan metode simpleks adalah Rp.850,000,- perproduksi setiap harinya.

Berikut langkah-langkah pemecahan PL menggunakan tools POM-QM For windows versi 3.0.

1) Saat program aktif maka akan otomatis dialihkan pada menu modul, untuk persoalan $\mathrm{Pl}$, maka pilih modul linier programming (lihat Gambar 2).

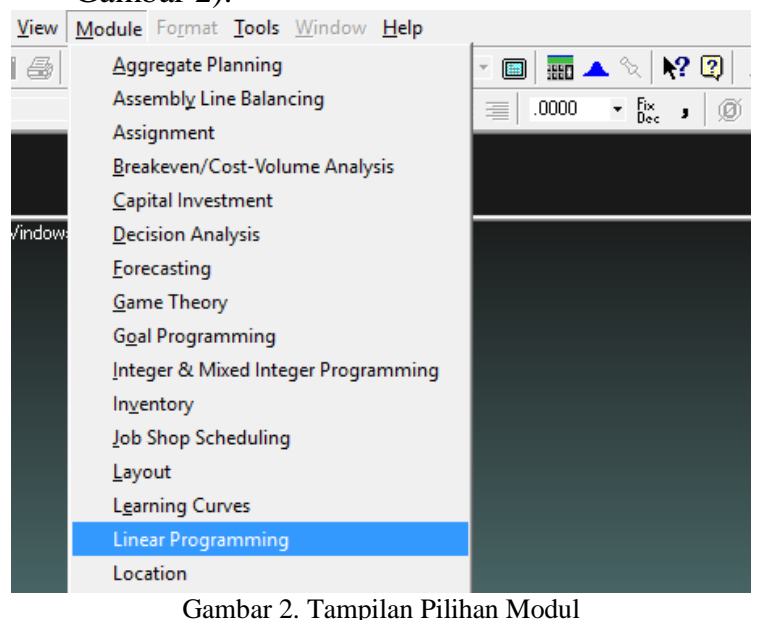

2) Kemudian untuk membuat file baru, pilih File $\rightarrow$ New (lihat Gambar 3).

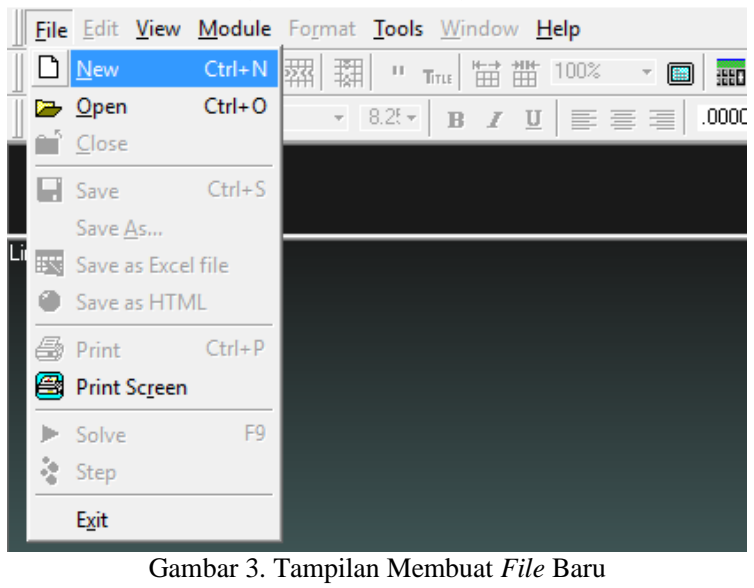

3) Kemudian memberi masukan pada file untuk data yang akan diolah, seperti judul, jumlah kendala/batasan, jumlah variabel keputusan, nama baris, dan nama kolom. Pada program ini 
tidak diperlukan lagi memasukkan pembatasan non-negatif (lihat Gambar 4).

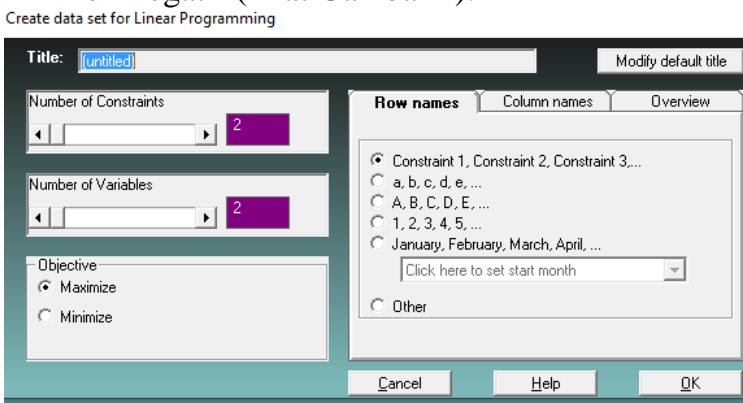

Gambar 4. Tampilan Masukan Data Linear Programming

4) Setelah itu memasukkan data produksi ke dalam kolom yang telah disediakan (lihat Gambar 5).

10. POM-QM for Windows - [Data Table]

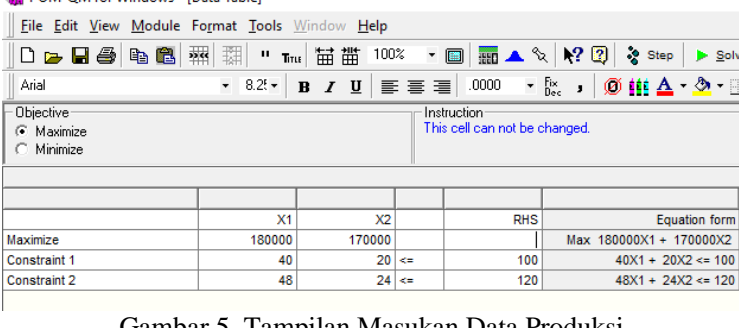

Gambar 5. Tampilan Masukan Data Produksi

5) Setelah data selesai dimasukkan kemudian pilih tombol solve lalu pilih menu Iterations. Maka akan diperoleh solusi pemecahan persoalan linear programming dengan metode Simpleks (lihat Gambar 6).

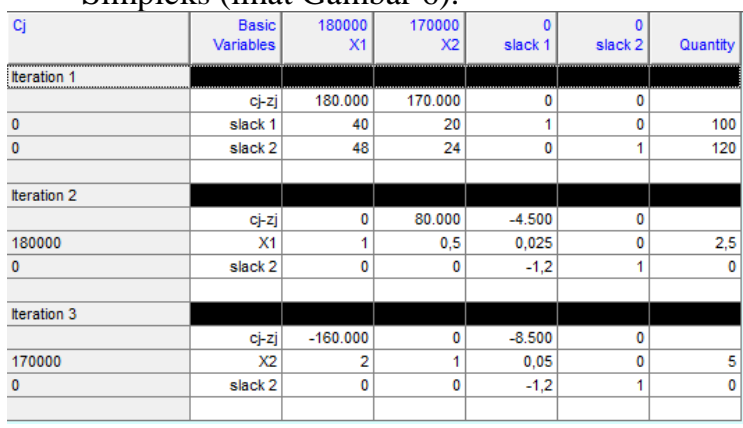

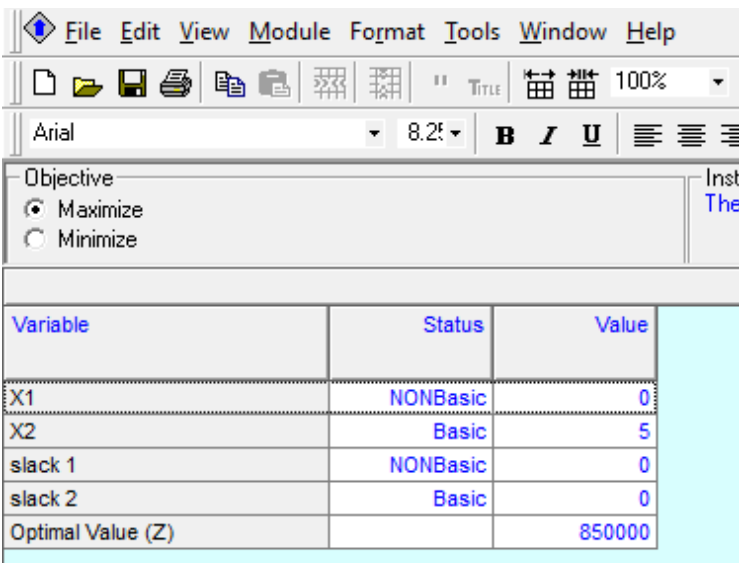

Gambar 6. Tampilan Pemecahan Masalah (solution)

Hasil analisis menunjukkan bahwa penerapan PL dengan menggunakan tools POM-QM for Windows dalam optimasi penjualan roti abon gulung dapat membantu dalam menghitung keuntungan maksimum dari hasil penjualan Roti Abon Gulung Sapi dan Ayam. Hasil analisis dengan menerapkan model PL dengan metode simpleks, keuntungan maksimal yang dapat diperoleh penjualan roti abon gulung yaitu sebesar Rp $\mathbf{8 5 0 , 0 0 0 , -}$ per produksi setiap harinya

\section{SIMPULAN}

Berdasarkan pembahasan tersebut, maka kesimpulan yang dapat diambil adalah:

1) Program Linier dalam hal ini metode simpleks dapat digunakan oleh penjualan roti abon gulung Hawai Bakery tersebut. Sehingga dengan keterbatasan sumber saya yang ada dapat dimanfaatkan untuk memperoleh keuntungan yang maksimal.

2) Pemanfaatan teknologi informasi yaitu tools POM-QM for windows sangat membantu perhitungan karena cepat, tepat serta akurat (efisien).

3) Metode simpleks dapat dijadikan acauan dalam pengambilan keputusan, karena mempercepat penjualan roti abon gulung Hawai Bakey untuk berinovasi dalam menghasilkan produk.

\section{DAFTAR PUSTAKA}

Budiasih, Y. (2018) 'Maksimalisasi Keuntungan Dengan Pendekatan Metode Simpleks Kasus Pada Pabrik Sosis SM', Liquidity, 2(1), pp. 59-65. doi: 10.32546/lq.v2i1.130.

Budiyanto, Mujiharjo, S. and Umroh, S. (2017) 'Maksimalisasi Profit pada Perusahaan Roti Bunda Bakery Menggunakan Metode Simplek', Agroindustri, 7(2), pp. 84-98.

Chandra, T. (2015) 'Penerapan Algoritma Simpleks dalam Aplikasi Penyelesaian Masalah Program Linier', Jurnal TIMES, IV(1), pp. $18-21$.

Firmansyah et al. (2018) 'PENGOPTIMALAN KEUNTUNGAN BADAN USAHA KARYA TANI DI DELI SERDANG DENGAN METODE SIMPLEKS', Journal of Islamic Science and Technology, 3(1), pp. 18-28. doi: 10.1017/CBO9781107415324.004.

Ismail, A. M. and Putra, D. E. (2017) 'Inovasi pembuatan abon ikan cakalang dengan penambahan jantung pisang', Agritech: Jurnal Fakultas Pertanian Universitas Muhammadiyah Purwokerto, 19(1), pp. 4554.

Jusniati, J., Patang, P. and Kadirman, K. (2017) 'Pembuatan Abon Dari Jantung Pisang (Musa Paradisiaca) Dengan Penambahan Ikan Tongkol (Euthynnus Affinis)', Jurnal 
12 Jurnal Jendela Ilmu, Vol. 1, No. 1, Juni 2020, hlm. 6-12

Pendidikan Teknologi Pertanian, 3(1), pp. 58-66. doi: 10.26858/jptp.v3i1.5198.

Nasution, Z. et al. (2016) 'PENERAPAN METODE SIMPLEKS UNTUK MENGANALISA PERSAMAAN LINIER DALAM MENGHITUNG KEUNTUNGAN MAKSIMUM', Jurnal Riset Komputer, 3(4), pp. 42-48.

Rico Ong et al. (2019) 'Maksimalisasi Keuntungan Pada Usaha Dagang Martabak Sucipto Menggunakan Metode Simpleks Dan POMQM', Jurnal Riset Komputer, 6(4), pp. 434-441.

Rumetna, M. S. et al. (2018) 'Penerapan Metode Simpleks Dan Software POM- QM Untuk Optimalisasi Hasil Penjualan Pentolan Bakso', Ilmiah Manajemen Informatika dan Komputer, 02(03), pp. 143-149.

Rumetna, M. S. et al. (2019) 'Pemanfaatan POMQM Untuk Menghitung Keuntungan Maksimum UKM Aneka Cipta Rasa (ACR) Menggunakan Metode Simpleks', Geotik, pp. 12-22. 